\title{
Synthesis of RGD peptides inducing multicellular spheroids formation
}

\author{
Maria Leko ${ }^{1}$, Anna Pokhvoshcheva ${ }^{1}$, Marina Dorosh $^{1}$, Roman Akasov $^{2}$, Elena Markvicheva ${ }^{2}$, Markus Weishaupt $^{3}$, \\ Thomas Bruckdorfer ${ }^{3}$, Sergey Burov ${ }^{1}$ \\ ${ }^{1}$ Medical-Biological Research-Industrial Complex CYTOMED, Russia \\ ${ }^{2}$ Shemyakin-Ovchinnikov Institute of Bioorganic Chemistry, RAS, Russia \\ ${ }^{3}$ Iris Biotech GmbH, Germany
}

https://doi.org/10.17952/35EPS.2018.096

\section{Introduction}

Availability of physiologically relevant in vitro models is one of the most important requirements determining the efficiency of drug screening process. Nowadays 2D monolayer cell culture represents one of the most employed in vitro methodologies for drug development. However, this simplified model with lack of cell-cell interactions is not able to adequately mimic the in vivo response.

Sutherland et al.[1] were first to propose multicellular tumor spheroids as a 3D model of small solid tumors. In contrast to 2D cell culture, 3D spheroids are able to mimic some features of solid tumors, including their spatial organization, physiological responses and drug resistance mechanisms. In the case of normal cells, multicellular spheroids (MS) are especially useful for the screening of neuroprotective agents, 3D bioprinting and tissue regeneration.

There are several classical protocols useful for MS formation, such as agarose, rotary, hanging drop and scaffold methods; however, each of them is limited by various factors. The most critical disadvantage is the absence of cellular and ECM interactions observed in vivo [2].

Recently we demonstrated the practical utility of a cyclic RGD peptide containing a triphenylphosphonium(TPP) moiety, namely cyclo-RGDfK(TPP), in a novel and highly reproducible one-step approach for MS formation[3]. The practical application of this technique requires development of simple and reliable protocol for the production of cyclic RGD peptides, containing TPP moiety.

Here we describe an optimized procedure for the synthesis of cyclo-RGDfK(TPP) and related peptides using our novel hydrazone resin[4].

\section{Results and Discussion}

There are numerous publications related to the synthesis of $c y c l o$-RGDfK peptide, including different variants of solution-phase and on-resin cyclization[5-7]. The suggested protocols imply cyclization of protected peptide precursor followed by subsequent removal of side-chain protecting groups.

Recently we described synthesis of inexpensive hydrazone resin and its practical utility for the preparation of peptide hydrazides[4]. These results prompted us to test possible advantages of azide method for the synthesis of cyclo-RGDfK(TPP) and related peptides. In order to compare the efficiency of various reaction protocols, the synthesis was performed in parallel on different polymer supports, namely Wang resin, $\mathrm{MBH}-\mathrm{Br}$ resin and Fmoc-hydrazono-pyruvoyl-aminomethylpolystyrene resin (Fig. 1). In preliminary experiments it was shown that attachment of the TPP moiety to the cyclic peptide in solution complicated the purification of the final product. Therefore, it was achieved by selective deprotection of Lys(Mtt)-containing peptidyl resin, followed by acylation with 4-carboxybutyltriphenyl phosphoniumbromide.

Surprisingly, using MBH resin the Mtt-deprotectionwith 1\% TFA in DCM resulted in peptide cleavage from the polymer support, while application of a mixture of AcOH/TFE/DCM (1:2:7) was inefficient (Fig. 2). 


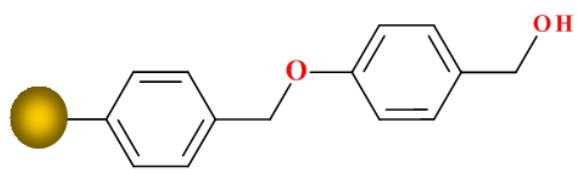

Wang Resin<smiles>C/C(=N\NCCF)C(=O)NCc1ccc(O)cc1</smiles>

Hydrazone Resin

(IRIS Biotech)

(A) H-Asp(OBzl)-D-Phe-Lys(R)-Arg-Gly-OH

1. HCTU

2. $\mathrm{HBr} / \mathrm{TFA}$

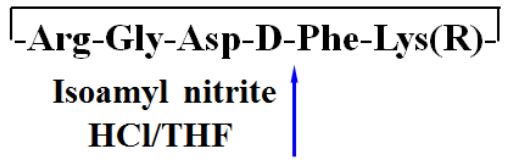

(B) H-Asp-D-Phe-Lys(R)-Arg-Gly- $\mathrm{N}_{2} \mathrm{H}_{3}$ $\mathrm{R}=\mathrm{X}-\mathrm{CO}-;\left(\mathrm{C}_{6} \mathrm{H}_{5}\right)_{3} \mathrm{P}^{+}-\left(\mathrm{CH}_{2}\right)_{4}-\mathrm{CO}-$

Figure 1: Synthesis of cyclic RGD peptides and their linear precursors. (A) Wang resin; (B) Hydrazone resin<smiles>Cc1ccc(C(Br)c2ccc(O)cc2)cc1</smiles>

MBH-Br Resin

\author{
H-Asp(OBzl)-D-Phe-Lys(Mtt)-Arg-Gly- \\ 1\% TFA/DCM $\star_{\text {AcOH/TFE/DCM }}$ \\ H-Asp(OBzl)-D-Phe-Lys-Arg-Gly- \\ H-Asp(OBzl)-D-Phe-Lys(Mtt)-Arg-Gly-OH
}

Figure 2: Deprotection of $\operatorname{Lys}(\mathrm{Mtt})$ resulted in peptide cleavage from $M B H$ resin (1\% TFA/DCM) or was inefficient (AcOH/TFE/DCM)

Synthesis on Wang resin provided linear peptide in reasonable purity. Its cyclization with HCTU proceeded smoothly without significant formation of dimeric side product. However, subsequent removal of the OBzl group from the aspartic acid residue by catalytic hydrogenolysis showed very low efficiency. Unexpectedly, the final peptide deprotection demanded drastic reaction conditions, such as two successive treatments with $\mathrm{HBr} / \mathrm{TFA}$ for 30 min and $1 \mathrm{~h}$.

The best results were obtained using hydrazone resin. Selective removal of the Mtt group had no influence on the stability of the hydrazone bond. Peptide cleavage from the solid support and removal of all protecting groups proceeded in one step. Cyclization of the resulting peptide hydrazide was achieved in good yield and purity 
using the azide method. These data evidence the practical utility of hydrazone resin for the synthesis of cyclic RGD peptides or their analogs containing cargo molecules.

The biological experiments have shown that both linear and cyclic RGD peptides containing TPP moiety efficiently suppress platelet aggregation. Withal, cyclo-RGDfK(TPP) is able to generate MS formation from tumor, normal or stem cell lines of various origin (Fig. 3). It was shown that suggested approach can be useful for the design of the original 3D in vitro co-culture models useful for the study of cell-cell interactions and invasion of different cell types. This novel one-step reproducible method of spheroid formation can be applied in the design of efficient in vitro models for the screening of novel drugs and drug delivery systems.

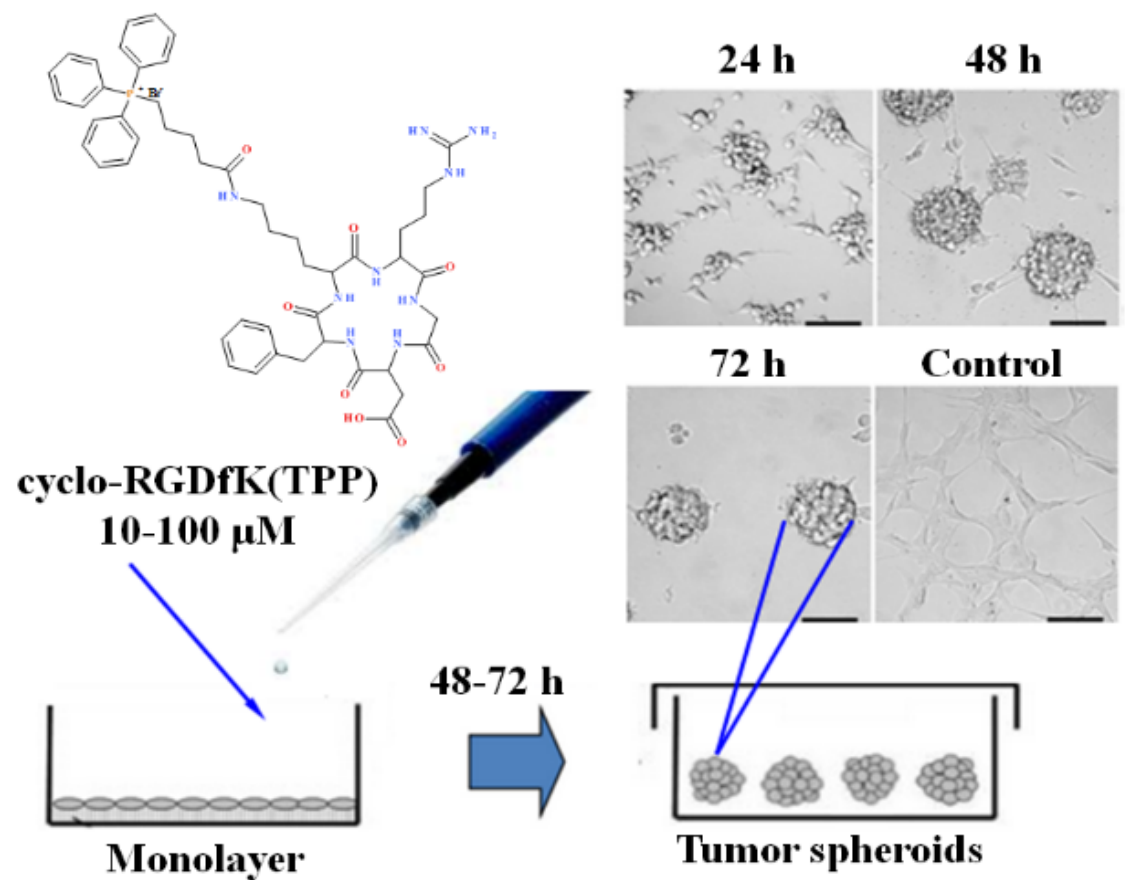

Figure 3: Experimental procedure for MTS formation using cyclo-RGDfK(TPP) method

Further experiments to clarify the mechanism of peptide action and its possible utility for tissue regeneration and wound healing are in progress.

\section{References}

[1] Sutherland R.M., McCredie J.A., Inch W.R. J. Natl. Cancer. Inst., 1971, 46, 113-120. DOI 10.1093/jnci/46.1.113.

[2] Sambi M., Qorri B., Frank S.M.S., Mouhamed Y., Kalaydina R.-V., Mendonza N., Szewczuk M.R. Curr. Top. Pept. Protein. Res. 2017, 18, 25-34.

[3] Akasov R., Zaytseva-Zotova D., Burov S., Leko M., Dontenwill M., Chiper M., Vandamme T., Markvicheva E. Int. J. Pharm. 2016, 506, 148-157. DOI: 10.1016/j.ijpharm.2016.04.005.

[4] Chelushkin P.S., Polyanichko K.V., Leko M.V., Dorosh M.Yu., Bruckdorfer T., Burov S.V. TetrahedronLett. 2015, 56, 619-622. DOI: 10.1016/j.tetlet.2014.12.056.

[5] Haubner R., Gratias R., Diefenbach B., Goodman S.L., Jonczyk A., Kessler H. J. Am. Chem. Soc. 1996, 118, 7461-7472. DOI: $10.1021 /$ ja9603721.

[6] Dai X., Su Z., Liu J.O. TetrahedronLett. 2000, 41, 6295-6298. DOI: 10.1016/S0040-4039(00)01060-1.

[7] McCusker C.F., Kocienski P.J., Boyle F.T., Schätzlein A.G. Bioorg. Med. Chem. Lett. 2002, 12, 547-549. DOI: $10.1016 /$ S0960-894X(01)00799-5 